\title{
Debate bubbles over the origin of life
}

\section{Could life have originated in geothermal ponds?}

Brian Switek

13 February 2012

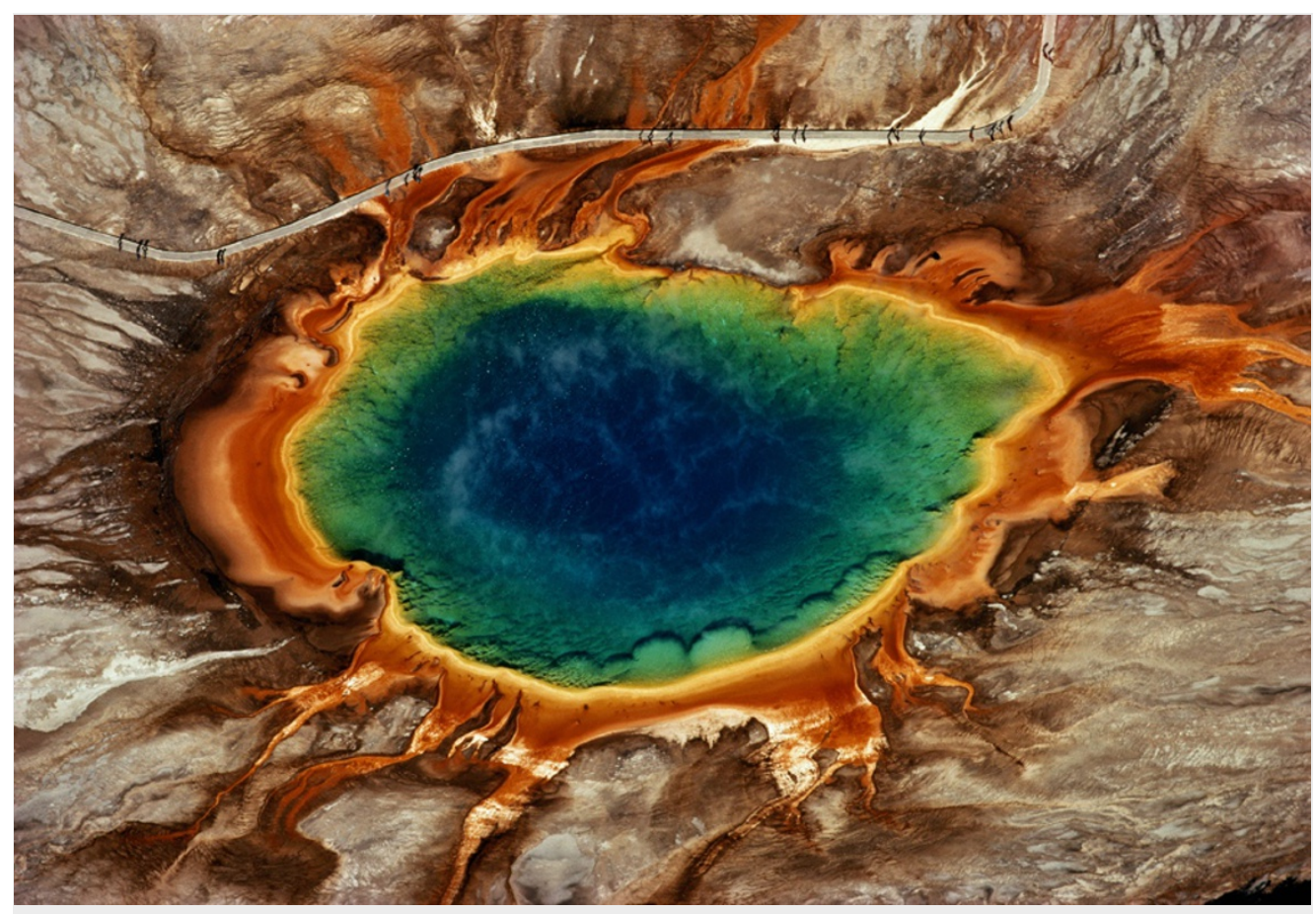

Paul Chesley/GETTY IMAGES

Geothermal ponds, like this one in Yellowstone National Park, could have been where the first cells evolved.

How life began is one of nature's enduring mysteries. Fossil and biological clues have led scientists to estimate that cells originated on this planet about four billion years ago, but exactly what catalysed their emergence has remained elusive.

In an 1871 letter to botanist Joseph Hooker, Charles Darwin wondered whether life might have begun "in some warm little pond, with all sorts of ammonia and phosphoric salts, light, heat, electricity, etc. present." Since then, scientists have come to conclude that life began in hydrothermal vents in the deep sea, but a controversial study published this week in Proceedings of the National Academy of Sciences ${ }^{1}$ argues that Darwin might have been on the right track.

The study, led by Armen Mulkidjanian of Germany's University of Osnabrück, suggests that inland pools of condensed and cooled geothermal vapour have the ideal characteristics for the origin of life. The conclusion is based mainly on the chemistry of modern cells. Citing an observation made in 1926 by biochemist Archibald Macallum that the composition of the cytoplasm of modern cells differs greatly from that of seawater ${ }^{2}$, and assuming that cells have changed little over the past four billion years led the researchers to propose that modern cell chemistry would provide clues about the type of environment in which life emerged.

Central to the hypothesis are the ions of particular metals - the new study is a follow-up to a 2009 paper in which Mulkidjanian and Michael Galperin suggested that the first cells developed in zinc-rich environments ${ }^{3}$. "In all living cells," Mulkidjanian says,"the cytoplasm is rich in potassium, zinc, manganese, and phosphate ions, which are not widespread in marine environments, and has lower amounts of sodium ions than outside."

Such conditions, the researchers argue, are found only where hot hydrothermal fluid brings the ions to the surface — places such as geysers, mud pots, fumeroles and other geothermal features. Within these fuming and bubbling basins, water laden with zinc and manganese ions could have collected and cooled in shallow pools which had drifted away from the geothermal "hot spots" as the Earth's crust shifted. Such pools could have been amenable to the development of life. Frustratingly, though, there is very little likelihood of finding direct evidence of such "hatcheries", as Mulkidjanian calls them, in the fossil record. Mulkidjanian notes that the 
primordial ponds would have been extremely acidic and therefore not preserved signs of the first life. He adds, however, that the ancient conditions could be modelled in the lab, "so at least some steps of the proposed scheme could be tested, and we are eager to promote such experiments and see their results"

\section{Expert dissent}

The study is already generating strong disagreement among other early-life experts. Nick Lane, a biochemist at University College London, UK, points out that the geothermal-pool hypothesis is problematic both biologically and geologically. "There was almost certainly very little land 4 billion years ago and terrestrial systems would have been unstable, short-lived, and severely limited in distribution," Lane says. Such conditions would have made it difficult for early life to gain a foothold, he says.

Lane also notes that the study has a significant conceptual flaw. "To suggest that the ionic composition of primordial cells should reflect the composition of the oceans is to suggest that cells are in equilibrium with their medium, which is close to saying that they are not alive," Lane notes. "Cells require dynamic disequilibrium — that is what being alive is all about."

Molecular biologist Jack Szostak of Harvard Medical School in Cambridge, Massachusetts, says that "geothermal active areas provide numerous advantages" and are a plausible staging area for the origin of life, but points out that we can't be sure that the chemistry of modern cells reflects the chemical conditions in which the first cells emerged. He disputes Mulkidjanian's claim that the high potassiumto-sodium ratio in modern cells is a sign of deep history, saying that instead, "it could still be that cells evolved the ability to generate and maintain a high potassium-to-sodium ratio in their cytoplasm for functional reasons, independent of the nature of their initial or early environment."

So rather than reflecting prehistoric environments, modern cell chemistry may indicate what sets life apart.

Nature | doi:10.1038/nature.2012.10024

\section{References}

1. Mulkidjanian, A. Y., Bychkov, A. Y., Dibrova, D. V., Galperin, M. Y. \& Koonin, E. V. Proc. Natl Acad. Sci. USA advance online publication http://dx.doi.org/10.1073/pnas.1117774109 (2012).

2. Macallum, A. B. Physiol Rev 6, 316-357 (1926).

3. Mulkidjanian, A. Y. \& Galperin, M. Y. Biol Direct 4, 27 (2009). 